\title{
Ducks change wintering patterns due to changing climate in the important wintering waters of the Odra River Estuary
}

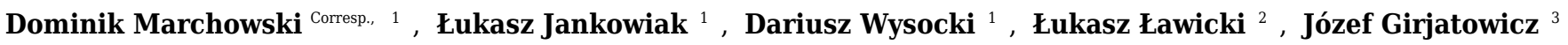 \\ 1 Department of Vertebrate Zoology and Anthropology, Institute for Research on Biodiversity, Faculty of Biology, University of Szczecin, Szczecin, Poland \\ 2 West- Pomeranian Nature Society, Szczecin, Polska \\ 3 Hydrography and Water Management Unit, Faculty of Earth Science, University of Szczecin, Szczecin, Poland \\ Corresponding Author: Dominik Marchowski \\ Email address: marchowskid@gmail.com
}

Some species of birds react to climate change by reducing the distance they travel during migration. The Odra River Estuary in the Baltic Sea is important for wintering waterfowl and is where we investigated how waterbirds respond to freezing surface waters. The most abundant birds here comprise two ecological groups: bottom-feeders and piscivores. Numbers of all bottom-feeders, but not piscivores, were negatively correlated with the presence of ice. With ongoing global warming, this area is increasing in importance for bottom-feeders and decreasing for piscivores. The maximum range of ice cover in the Baltic Sea has a weak and negative effect on both groups of birds. Five of the seven target species are bottom-feeders (Greater Scaup Aythya marila, Tufted Duck $A$. fuligula, Common Pochard A. ferina, Common Goldeneye Bucephala clangula and Eurasian Coot Fulica atra), and two are piscivores (Smew Mergellus albellus and Goosander Mergus merganser). Local changes at the level of particular species vary for different reasons. A local decline of the Common Pochard may simply be a consequence of its global decline. Climate change is responsible for some of the local changes in the study area, disproportionately favoring some duck species while being detrimental to others. 
1 Ducks change wintering patterns due to changing climate in the important

2 wintering waters of the Odra River Estuary

3

4 Dominik Marchowski ${ }^{1, *}$, Łukasz Jankowiak ${ }^{1}$, Dariusz Wysocki ${ }^{1}$, Łukasz Ławicki ${ }^{2}$, Józef

5 Girjatowicz ${ }^{3}$

6

7

$8{ }^{1}$ Department of Vertebrate Zoology and Anthropology, Institute for Research on Biodiversity,

9 Faculty of Biology, University of Szczecin, Szczecin, Poland

$10 \quad{ }^{2}$ West-Pomeranian Nature Society, Szczecin, Poland

$11{ }^{3}$ Hydrography and Water Management Unit, Faculty of Earth Science, University of Szczecin,

12 Szczecin, Poland

$13 \quad$ Corresponding author: Dominik Marchowski marchowskid@gmail.com

14

15

16

17 


\section{Abstract}

Some species of birds react to climate change by reducing the distance they travel during migration. The Odra River Estuary in the Baltic Sea is important for wintering waterfowl and is where we investigated how waterbirds respond to freezing surface waters. The most abundant birds here comprise two ecological groups: bottom-feeders and piscivores. Numbers of all bottom-feeders, but not piscivores, were negatively correlated with the presence of ice. With ongoing global warming, this area is increasing in importance for bottom-feeders and decreasing for piscivores. The maximum range of ice cover in the Baltic Sea has a weak and negative effect on both groups of birds. Five of the seven target species are bottom-feeders (Greater Scaup Aythya marila, Tufted Duck A. fuligula, Common Pochard A. ferina, Common Goldeneye Bucephala clangula and Eurasian Coot Fulica atra), and two are piscivores (Smew Mergellus albellus and Goosander Mergus merganser). Local changes at the level of particular species vary for different reasons. A local decline of the Common Pochard may simply be a consequence of its global decline. Climate change is responsible for some of the local changes in the study area, disproportionately favoring some duck species while being detrimental to others.

\section{Introduction}

Migration distance has declined in several species of aquatic (and other) birds as a result of climate change (Musil et al. 2011; Lehikoinen et al. 2013; Meller 2016). The distances that birds migrate from their breeding areas in northern and eastern Europe to their central European wintering areas are shorter during mild winters (Lehikoinen et al. 2013; Pavón-Jordan et al. 2015); conversely birds may change their wintering sites to warmer regions during colder 
41 periods because they may perceive local manifestations of larger scale weather (Newton 2008).

42 Reducing migration distance can provide several benefits associated with earlier arrival at the

43 breeding grounds and greater survival (Coppack and Both 2002; Jankowiak et al. 2015a; 2015b).

44 Food resources of wintering sites may also influence migration decisions (Cresswell 2014;

45 Aharon-Rotman et al. 2016). Although winter site fidelity is usually very strong among

46 waterfowl (Newton 2008), this can change in response to weather, habitat, and competition

47 (Cresswell 2014). Changing winter sites may often be a trade-off between the costs of finding a

48 new site and the benefits it offers (Aharon-Rotman et al. 2016). At sub-zero temperatures,

49 shallow waters freeze over; forcing birds to expend more time and energy searching for food in

deeper, open waters. Three functional groups of waterbirds forage in the shallow waters of

51 offshore lagoons: piscivores, herbivores and bottom-feeders, for example, large numbers of

52 waterbirds gather to forage in the Odra River Estuary (hereafter ORE) (Marchowski et al. 2015;

53 Marchowski et al. 2016). Two groups of waterbirds - bottom-feeders and piscivores - are among

54 those most commonly wintering here. During winter, the study area is subject to wide variation

55 in temperatures, often making surface waters subject to freezing (van Erden and de Leeuw 2010).

56 Yet even relatively small variations in temperature, causing ice cover to form or disappear, can

57 lead to the displacement of waterbirds. Changes in abundance and community structure of birds

58 in the ORE may reflect the impact of climate change. Analysis of the dates of the appearance of

59 ice-related phenomena in the Szczecin Lagoon and of their frequency over time reveals a distinct

60 pattern illustrating recently observed trends in climate warming (Girjatowicz 2011). In this

61 paper, we are looking for how the abundance of some species in the ORE changes due to climate

62 warming. We are investigating whether climate change will differentially influence foraging

63 patterns, and consequently overwintering patterns, of these two groups of birds. Thus, increasing 
64 temperatures due to climate change, and the shorter time interval with ice cover will result in 65 increasing numbers of bottom-feeders because they will then migrate shorter distances. Frosts in

66 the study area are never so severe that the water freezes completely to the bottom even in the 67 shallows. But even if ice does cover the surface of shallow water bottom-feeders have no access 68 to food and have to move to warmer areas because feeding areas where sedentary mussels are 69 abundant tend to be in shallow waters (Marchowski et al. 2015). Piscivores, on the other hand, 70 can still feed in such conditions (frozen surface of shallows, unfrozen deeper areas - further from 71 the shore, where there are no mussels but there are fish) and remain in the area, e.g. observation 72 of large aggregations of piscivores during harsh winters (Smew Mergellus albellus and 73 Goosander Mergus merganser) (Kaliciuk et al. 2003; Czeraszkiewicz et al. 2004; Marchowski 74 and Ławicki 2011; Guentzel et al. 2012; Marchowski and Ławicki 2012; Marchowski et al. 75 2013). This has consequences for conservation management plans in protected areas. Two 76 different groups of birds react differently to climate warming, showing different patterns of 77 moving closer to their breeding grounds, as a consequence in our area should be more bottomfeeders. Thus, changes in the importance of wintering ground due to changing surface-water 79 freezing patterns expected under global warming regimes are likely to have important consequences for very large numbers of these birds.

\section{Study area} Estuary system, which includes the Great Lagoon (the Polish part of the Szczecin Lagoon),

84 Świna Backward Delta, Kamień Lagoon, Dziwna Strait and Lake Dąbie (522.58 km2, Fig. 1). The area comprises four interconnected Important Bird Areas (IBA) and also a Natura 2000 area 86 (Wilk et al. 2010). The average and maximum depths of the estuary are 3.8 and $8.5 \mathrm{~m}$, 
87 respectively; the dredged shipping lane passing through the estuary from the Baltic Sea to the

88

89

90

91

92

93

94

95

96

97

98

99

100

101

102

103

104

105

106

107

108

109 port of Szczecin is $10.5 \mathrm{~m}$ deep (Radziejewska and Schernewski 2008). Waters of the Szczecin Lagoon, Kamień Lagoon, and Lake Dąbie are brackish. Salinity in the central part of the estuary varies from $0.3 \mathrm{psu}$ to $4.5 \mathrm{psu}($ mean $=1.4 \mathrm{psu})$ and declines with increasing distance from the sea (Radziejewska and Schernewski 2008). Average winter temperature is $0.3^{\circ} \mathrm{C}$ (Weatherbase 2016). The ORE is subject to high levels of eutrophication (Radziejewska and Schernewski 2008). Communities of benthic organisms are typical of freshwater bodies, and the fauna includes large populations of zebra mussels Dreissena polymorpha, which was introduced in the mid-19th century. By the 1960s, the biomass of zebra mussels in the Szczecin (Great) Lagoon was estimated at 110000 metric tons (Wiktor 1969, Wolnomiejski and Woźniczka 2008). The distribution of the zebra mussel is extremely uneven (see the map in Marchowski et al. 2015). The average density of the zebra mussel in the ORE is $0.18 \mathrm{~kg} / \mathrm{m}^{2}$, but the vast majority occupies around $10 \%$ of the area, where the mean density is $2.05 \mathrm{~kg} / \mathrm{m}^{2}$ (Stańczykowska et al. 2010). Fish are mainly freshwater species such as roach Rutilus rutilus, bream Abramis brama, pike Esox lucius, perch Perca fluviatilis and ruff Gymnocephalus cernua; there are also anadromous fish including smelt Osmerus eperlanus and occasionally herring Clupea harengus among others (Wolnomiejski and Witek 2013).

\section{Methods}

\section{Bird censusing}

The study covers two functional groups of waterbirds: bottom-feeders (diving birds, feeding on motionless type of food - mussels) - Greater Scaup (Aythya marila - hereafter Scaup), Tufted Duck (A. fuligula), Common Pochard (A. ferina - hereafter Pochard), Common Goldeneye (Bucephala clangula - hereafter Goldeneye) and Eurasian Coot (Fulica atra - 
110 hereafter Coot); piscivores (diving birds, feeding on mobile type of food - fish) - Smew and

111 Goosander (Stempniewicz 1974; Johansgard 1978). Six of our target species belong to the order:

112 Anseriformes, family: Anatidae, subfamily: Anatinae and Tribe: Mergini (Goldeneye, Smew and

113 Goosander), Tribe: Aythyini (Scaup, Pochard and Tufted Duck); one species - Coot belongs to

114 the order: Gruiformes, family: Rallidae (del Hoyo and Collar 2014). Although Coot is not closely

115 related to the rest of our species, we included it into a common group of waterbirds and, due to

116 its behavior and ecology, to the bottom-feeders group (Stempniewicz 1974). These seven species

117 are usually very abundant in the study area (Kaliciuk et al. 2003; Czeraszkiewicz et al. 2004;

118 Wilk et al. 2010; Marchowski and Lawicki 2011; Guentzel et al. 2012; Marchowski and Ławicki

119 2012; Marchowski et al. 2013). These are important gathering areas for populations of these

120 birds associated with regional migration flyways. These subpopulations (hereafter regional or

121 flyway populations) are: Pochard - north-east Europe / north-west Europe; Tufted Duck - north-

122 west Europe (wintering); Scaup - northern Europe / western Europe; Goldeneye - north-west

123 and central Europe; Smew - north-west and central Europe (wintering); Goosander - north-west

124 and central Europe (wintering); Coot - north-west Europe (wintering) (Wetlands International 125 2016).

Censuses were conducted using standard methods for non-breeding season waterbirds counts (Komdeur et al. 1992; Wetlands International 2010). Birds were counted during 17

128 seasons (1991/1992 to $1993 / 1994$ and $2001 / 2002$ to $2015 / 2016)$ during the migration and 129 wintering periods between November and April. Three censuses were carried out per season in 130 November, January, and March or April; there was one midwinter count in January in 131 2001/2002. Altogether we analyzed the results of 44 counts. Most counts were done on foot. 132 Each observer was equipped with 10x binoculars and tripod-mounted spotting scopes. Observers 
133 walked along the same routes, and the same counting method was used during every census

134 every year. Additionally, fourteen aerial counts were made at an average speed of about 100

$135 \mathrm{~km} / \mathrm{h}$ and an altitude of about $80 \mathrm{~m}$ above the water (see supplementary materials - S1 Table for

136 the method of data collection: aerial or ground). In the early 1990s, counts were aerial, whereas

137 in 2009-2015 parallel aerial and ground counts were carried out (to compare methods). In ice-

138 free conditions, the species covered in this study can be assigned to a group with just a small

139 error between methods $(<6 \%)$, one species - Coot had a moderate error $(16 \%)$, the ground

140 method estimated greater numbers than the aerial one. During periods with more than $70 \%$ ice

141 cover, abundance estimated from the air was greater than that estimated from the ground

142 (Dominik Marchowski pers. com.). Count method was treated as a random effect in the model.

143 The detailed methodology and results of the counts are given elsewhere (Meissner and

144 Kozakiewicz 1992; Meissner et al 1994; Kaliciuk et al. 2003; Czeraszkiewicz et al. 2004;

145 Marchowski and Ławicki 2011; Guentzel et al. 2012; Marchowski and Ławicki 2012;

146 Marchowski et al. 2013). Where large numbers of unidentified Aythya species were counted - 26

147000 ducks in November 2009, 13000 in November 2010, 6000 in January 2012, 3300 in March

1482012 and 13500 in November 2015 - they were estimated to be in the ratio of 1:0.8

149 (scaup:tufted) based on observations in other studies. Observations were always at a distance that

150 does not disturb the birds in any way, and in Poland, this research required no ethical or 151 scientific permits.

\section{Statistical analysis}

Absolute numbers of birds can vary widely and independently, and so the proportion of

154 the local population size (in our study area) in relation to flyway population for each species was 155 used as our dependent variable (Nagy et al. 2014; Wetland International 2016). Thus, if we used 
156 the trend of absolute numbers in our area, the resulting error would be the larger, the greater the 157 changes in the size of the flyway population. Therefore, we indicate the numbers of a species by

158 means of a coefficient calculated as the percentage of the flyway population present in the study 159 area during a particular count. We obtained the regional population size estimates from 1992 to 1602012 from Nagy et al. (2014); for the period 2013-2016, we used the flat trend calculated by 161 Nagy et al. (2014) (Table 1). Initially, we placed the different species in ecological groups. The 162 bottom-feeders (denoted by B) included Scaup, Tufted Duck, Pochard, Goldeneye and Coot, and 163 the piscivores (P) contained Smew and Goosander. We used the minimum temperatures 164 averaged over the 15 days leading up to the count day. The climate data were obtained from the 165 Szczecin weather station (53.395 N, 14.6225 E, http://tutiempo.net). Another climate covariate 166 was ice cover in the study area; data relating to this were published by the Polish Institute of 167 Meteorology and Water Management. These data are from the observation point at Miroszewo 168 on the shore of the Szczecin Lagoon (53.734 N, 14.331 E, http://www.imgw.pl/). We compared 169 the number of days with $100 \%$ ice cover in the period from 0 to 15 days prior to the bird counts.

170 The ice cover of $100 \%$ refers specifically to the Miroszewo observation point. This estimate is a 171 good approximation for the region. In practice, however, the ORE is never completely covered 172 by ice (Girjatowicz 1991; 2005; see the Discussion for an explanation) and birds are still present 173 in such conditions. We also utilized the maximum ice extent in the Baltic Sea (max ice; data 174 obtained from the website of The European Environment Agency; EEA 2017). Apart from 175 climatic variables, we also tested the changes in species occurrence during the survey years, so 176 we used the season as a covariate. Prior to the final analysis, we checked multicollinearity 177 between the above variables using the variation inflation factor (VIF). VIFs of all variables were 178 in acceptable limits, minimum temperatures $(\mathrm{VIF}=2.1)$, max ice $(\mathrm{VIF}=1.03)$, ice cover $(\mathrm{VIF}=$ 
179 2.07) and season $(\mathrm{VIF}=1.04)$. However, we found a moderate linear significant relationship

180 between minimum temperature and ice cover $(\mathrm{r}=0.52, \mathrm{p}<0.001)$ and after exclusion of minimal

181 temperature VIF showed no multicollinearity issue between variables - ice cover (VIF $=1.04)$,

$182 \max$ ice $(\mathrm{VIF}=1.03)$, season $(\mathrm{VIF}=1.03)-$ and these were used in the subsequent analyses.

183 Frozen water by definition impedes bottom-feeding duck foraging, we are testing whether that

184 pattern is changing in association with climate change. We used a general linear mixed model

185 (GLMM) to test above-described relationship. The percentage of the flyway population present

186 in the study area, estimated by species, was used as a target variable using the normal

187 distribution response distribution and identity link function. Mixed models permitted repetition

188 across survey months, methods (aerial and ground counts) and species (random intercept). Thus,

189 to test our assumptions we included the following interactions: feeding group*season, feeding

190 group*ice cover and feeding group*max ice. Selection of the best model structure for the

191 dependent variable was based on the Akaike information criterion (AIC) (Zuur et al. 2009). All

192 possible models were carried out (they are listed in Table S1 in Supplementary material). As the

193 final models, we assumed those in which $\triangle \mathrm{AIC}<2$ (Burnham \& Anderson 2002) and in our

194 case, it was only a general model with all the tested variables. To test the relationship between

195 explanatory variables and particular species abundance we performed for each species GLMM

196 model, where random effects were month and method. We checked also the relationship between

197 winter year and ice cover using a generalized linear model with negative binomial error

198 distribution. We used IBM SPSS Statistic version 20 software for the statistical analysis. P <

1990.05 was considered statistically significant.

\section{Results}



groups - piscivores and bottom-feeders and the second one where each species were analyzed.

203

204

205

206

207

Bird numbers by feeding group were different in their relationships with ice cover, bottomfeeding species in the study area were more sensitive to lower temperatures and left sooner when colder weather increased ice cover, whereas numbers of piscivorous species had a higher tolerance to the extent of ice cover (Table 2). Interactions between feeding group and season, feeding group and ice cover, and feeding group and maximum ice extent on the Baltic sea were all important (Table 2). However, the strongest effects were interactions with ice cover, then interaction with the season, this translates into increases in the importance of the site for bottomfeeders. The effect of maximum ice extent was very small (Table 2). Population indices in the ORE changed over the last 25 years, increased in the case of bottom-feeding species but decreased for piscivorous species (Table 2). Ice cover across the whole Baltic Sea had the same, though weak, impact on both functional groups of birds, numbers of birds in the ORE declined with expanding ice cover in the Baltic (Table 2).

Where particular species are concerned, the situation is more complex. The population indices of Scaup and Tufted Duck in the ORE exhibited an increasing trend $\left(\beta_{\text {Scaup }}=0.026 \pm 0.010\right.$ s.e.,$p=0.011$; however for Tufted Duck marginally insignificant $\beta=0.008 \pm 0.004$ s.e., $p=0.058$ ), despite the general decline in their entire northern and western European populations; numbers of both species in the ORE were adversely affected by ice cover in that region $\left(\beta_{\text {Scaup }}=-0.065 \pm 0.011\right.$ s.e., $p<0.001 ; \beta_{\text {Tufted }}=0.032 \pm 0.005$ s.e., $\left.p<0.001\right)$ but not by ice cover in the whole Baltic $\left(\beta_{\text {Scaup }}=-0.099 \pm 0.074\right.$ s.e. $p=0.186 ; \beta_{\text {Tufted }}=0.010 \pm 0.029$ s.e., $\left.p=0.735\right)$. Relative numbers of Pochard in the ORE have declined $(\beta=-0.009 \pm 0.003$ s.e.,$p=0.005)$, but so has the whole northern European population, abundance was negatively impacted by ice cover in 
224 both the study area $(\beta=-0.015 \pm 0.003$ s.e., $p<0.001) ;$ and in the entire Baltic $(\beta=-$

$2250.053 \pm 0.023$ s.e., $p=0.023)$. For Goldeneye, the index for the ORE population was unchanged $(\beta=-$ $2260.004 \pm 0.004$ s.e., $\mathrm{p}=0.275$ ), despite the increase in the European population, abundance was 227 negatively impacted by ice cover in the study area $(\beta=-0.016 \pm 0.004 \mathrm{~s} . \mathrm{e} ., \mathrm{p}<0.001)$, but not by ice 228 cover in the entire Baltic $(\beta=-0.044 \pm 0.027$ s.e., $p=0.107)$. Relative numbers of Coot in the ORE 229 remained unchanged $(\beta<0.001 \pm 0.002$ s.e., $\mathrm{p}=0.915)$, despite the slight increase in the European 230 population, abundance was negatively impacted by ice cover in both the study area ( $\beta=$ $2310.014 \pm 0.003$ s.e., $p<0.001)$, and in the entire Baltic $(\beta=-0.038 \pm 0.016$ s.e., $p=0.019)$. The ORE 232 population index for Smew decreased $(\beta=-0.020 \pm 0.008$ s.e., $p=0.024)$, despite the increase in its 233 flyway population, abundance in the ORE was unaffected by ice cover either in the study area $234(\beta=-0.013 \pm 0.010$ s.e.,$p=0.183)$, or in the Baltic as a whole $(\beta=-0.079 \pm 0.061$ s.e.,$p=0.204)$. Finally, 235 relative numbers of Goosander in the ORE remained unchanged $(\beta=-0.005 \pm 0.008$ s.e., $p=0.572)$, 236 like those of the whole population wintering in north-western and central Europe; abundance in 237 the ORE was unaffected by ice cover either in the study area $(\beta=0.018 \pm 0.009$ s.e.,p $=0.063)$ or in 238 the Baltic as a whole $(\beta=-0.111 \pm 0.057 \mathrm{~s} . \mathrm{e} . \mathrm{p}=0.057)$. The details relating to all these species are 239 listed in Table 1, presented in Fig. 2A and Table S3. Table 3 summarizes the changes in the 240 importance of the ORE for wintering populations of diving waterbirds in the last 25 years. There 241 was positive relationship between year and winter ice (beta0 $=82.011$, s.e. $=28.49$, beta winter=2420.040 , s.e. $=0.0142$, Chi-square $=8.001, \mathrm{df}=1, \mathrm{p}=0.005$; Figure 2B).

\section{Discussion}

The phenomenon of freezing in our study area has decreased over time (Girjatowicz 246 2011, Fig 2 B), so that target birds species should tend to feed more recently more often than in 
247 the past. However, two functional groups of waterbirds - bottom-feeders and piscivores - react

248 differently to ice cover, a factor that is directly connected to climate change; this has

249 consequences for the wintering patterns of these species. Bottom-feeding birds (Scaup, Tufted

250 Duck, Pochard, Goldeneye, nd Coot) tend to be more sensitive to ice cover in the study area than

251 piscivores (Smew and Goosander). Piscivores can survive in colder areas, closer to their

252 breeding ranges, but bottom-feeders have to move further south and west. This phenomenon

253 indicates that piscivores are declining in our study site because they are shifting further north and

254 east in order to stay closer to their breeding areas. Bottom-feeders are increasing their number for

255 the same reason - they, too, are moving further north and east - but in their case, he result is a

256 greater number in our study area and a smaller one in areas further west and south. Bottom-

257 feeding birds forage in the ORE mainly on mussels of the genus Dreissena (Marchowski et al.

258 2015, 2016); the highest quality of this food resource is found in water 1-2 $\mathrm{m}$ deep

259 (Wolnomiejski and Witek 2013). Shallow water freezes over faster, displacing birds to deeper

260 unfrozen areas where food is accessible only with difficulty. In addition, when ice cover is

261 present, the abundance of food in unfrozen areas declines owing to its greater exploitation,

262 because the birds congregate on a limited area. In the case of piscivorous birds increasing ice

263 cover not affect their numbers negatively. The ORE is never completely covered by ice: the

264 shipping lane between Świnoujście and Szczecin is kept free of ice (Girjatowicz 1991; 2005),

265 and there are always other areas free of ice, especially at the mouths of the small rivers flowing

266 into the estuary. These ice-free areas may still abound in fish and provide food for piscivores. In

267 general, there is growing importance of the study area for the bottom-feeders. The main analysis

268 jointly examines two whole groups - piscivores and bottom-feeders; the results of it are the

269 positive effect of not freezing for bottom-feeders and negative effect for piscivores, and also a 
270 positive effect of the season for bottom-feeders, and negative effect for piscivores (see Table 2).

271 In the other analysis, which examined each species separately, there are differences between

272 them (see Fig. 2A). As far as the most numerous species - Scaup and Tufted Duck - are

273 concerned, the results tally with those of the first analysis, i.e. their numbers are increasing

274 (correlation with season). For the less abundant species, the result of the second analysis is

275 different: Pochard numbers, for example, are decreasing (negative effect). In the first analysis,

276 abundance and season were negatively correlated in piscivores. In the second analysis, in which

277 we examined species separately, abundance and season were independent in the Goosander,

278 while abundance and season were negatively correlated in the Smew. In fact, the strongest effect

279 of the first years of the study relates to the piscivores, especially Smew. If we take the entire

280 period (1992 - 2016), the Smew declines in numbers (confer with model results), which was due

281 to their being very abundant in the early 1990s. From $2002-2016$, Smew numbers are stable.

282

283

284

285

286

287

288

289

290

291

292
An interesting result is the negative effect of maximum ice cover in the entire Baltic Sea

on the numbers of all species in our study. This is unexpected since our study area is in the warmer south-western Baltic, where one would anticipate an increase in the number of waterbirds in such circumstances (Alerstam 1990). The explanation for this relationship is not easy and certainly goes far beyond the scope of this work, but we can speculate on possible scenarios. On maps with the maximum range of ice cover in the Baltic Sea we can see clearly that when the northern Baltic, i.e. the Gulf of Bothnia and the Gulf of Finland, is completely frozen over, the entire Pomeranian Bay (SW Baltic) (see the map - Fig.1) together with the ORE is also covered with ice (Finnish Meteorological Institute 2017). These areas freeze over quickly because of their shallowness and low salinity, the latter being due to the considerable influence of fresh water from the Odra river basin. Consequently, during harsh winters, birds from 
293 northern Baltic move to the south and west, but they by-pass our study area as it is covered by

294 ice. Under such circumstances, there may sometimes be better conditions for waterbirds in areas

295 farther north, e.g. the southern coast of Sweden, where there is no ice cover (Finnish

296 Meteorological Institute 2017). Worth noting here, however, is that such cold weather causing

297 the entire Pomeranian Bay and Odra River Estuary to freeze over is rare and becoming rarer 298 (EEA 2017).

The global temperature has risen about $1{ }^{\circ} \mathrm{C}$ over the last 130 years, and Northern 300 Hemisphere temperatures of the last 30 years have been the highest in over 800 years (Stocker et al. 2013). The extent and duration of ice cover in the Baltic have decreased on average by 50\% over the last 36 years (Schröder 2015). There is evidence that the range and occurrence of migratory birds have changed in response to climate change and that some species have shortened their migratory movements by wintering closer to their breeding areas (Musil at al. 2011; Lehikoinen et al. 2013; Pavon-Jordan et al. 2015; Meller 2016). Assuming continued climate warming, the negative correlation between numbers of bottom-feeding birds and the number of days with ice cover indicates that the ORE is becoming more important for this group of birds. Climate change seems to be the primary reason for increases (in the study area) in numbers of Scaup and Tufted Duck and decreases in numbers of Smew; this corresponds with the findings of Lehikoinen et al. (2013) in the case of Tufted Duck and of Pavón-Jordan et al.

311 (2015) in the case of Smew. Our results are important for conservation planning. Declines in the 312 flyway populations of species such as Scaup and Tufted Duck, even though the importance of 313 our study area to these species is increasing, but at the same time, there is an increase in exposure 314 to locally emerging threats. The biggest threats to these species in the area include fishery 315 bycatches (Žydelis et al. 2009; Bellebaum et al. 2012). The ecology of diving birds makes this 
316 type of threat responsible for the extra mortality of all species covered by this study. Comparison

317 of a species' estimated total population numbers (Nagy et al. 2014) with numbers for the ORE is

318 interesting, since local trends and European trends do not always concur. The different responses

319 of particular species to the factors investigated are also worth examining. We grouped the

320 species by trends in the study area and discuss these for each species below.

\section{Species with increasing population index in the study area}

Between the late 1980s and 2012, the population of Scaup wintering in northern and western Europe declined at an annual rate of 3.57\%/year (Nagy et al. 2014). Around $41 \%$ of the

Scaup from this population spent the winter in the Baltic Sea region (Skov et al. 2011), and this, in turn, declined by 60\% from 1991 to 2010 (Aunins et al. 2013). At the same time, we found that the importance of the ORE for this species was increasing. Scaup numbers increased by $300 \%$ in the Szczecin Lagoon (the biggest part of Odra River Estuary - see the map - Fig. 1) and the eastern coastal areas of Germany, as opposed to declines further west along the German coast, where some areas (Wismar Bay and Traveförde) had fewer birds than 15 years earlier (Skov et al. 2011). A similar trend was found in Sweden, where the number of wintering Scaup increased between 1971 and 2015 (Nilsson and Haas 2016). But farther west, in the Netherlands, Hornman et al. (2012) recorded decreases at the most important wintering sites since 1980/1981. All of these studies confirm that Scaup is shifting its wintering range northwards and eastwards, closer to its breeding areas: this is the reason for the heightened importance to this species of the ORE, even as its overall population wintering in northern and western Europe is declining. 
338 Europe flyway remained relatively stable between 1987 and 2009 (Lehikoinen et al. 2013), a

339 situation confirmed by Wetlands International (2016). In the Baltic Sea region, too, there were

340 no significant changes in numbers between 1991 and 2010 (Aunins et al 2013). We have found

341 that our study area has increased in importance for this species, although not to the same extent

342 as for Scaup. Swedish populations, by comparison, have increased between 1971 and 2015

343 (Nilsson and Haas 2016), and Lehikoinen et al. (2013) reported a rapid increase in the last three

344 decades for Finland. Tufted Ducks in the ORE behave in the same way as Scaup in that they

345 form mixed flocks consuming the same type of food (Marchowski et al. 2016). At a larger scale,

346 Tufted Ducks have a different migration and wintering strategy: Scaup concentrate in a few hot

347 spots, moving jump-wise between them, whereas the distribution of Tufted Ducks is more

348 diffuse (van Erden and de Leeuw 2010; Skov et al. 2011; Neubauer et al. 2015; Carboneras and

349 Kirwan 2016a; Carboneras and Kirwan 2016b). This could cause Tufted Ducks to disperse to

350 smaller water bodies outside our study area, e.g. the numerous lakes in the Pomeranian Lake

351 District in northern Poland $\left(\sim 34000 \mathrm{~km}^{2}\right)$, whereas Scaup remains almost exclusively in the

352 ORE (e.g. Marchowski and Lawicki 2011; Marchowski et al. 2013). Scaup is known to

353 concentrate in big flocks during migration and wintering, and the whole flyway population may

354 be concentrated in a few hot-spots such the ORE (Marchowski et al. 2015): this is important in

355 the context of species conservation planning. There is an increase in the importance of the ORE

356 for Scaup, but at the same time, there is an increase in exposure to locally emerging threats such

357 as bycatches in fishing nets (Bellebaum et al. 2012). Taking into account the above pattern of

358 Scaup behavior and our results, there is a justified fear that locally operating threats in the ORE

359 may affect the entire flyway population of the species. This is one of the most important

360 messages of our work. 
361

362

363

364

365

366

367

368

369

370

371

372

373

374

375

376

377

378

379

380

381

382

383

\section{Species with decreasing population index in the study area}

Pochard populations from north-east/north-west Europe have declined rapidly at an annual rate of 3.35\%/year (Nagy et al. 2014). Pochard numbers in the Baltic Sea region also declined by 70\% between 1991 and 2010 (Aunins et al. 2013). In 1995 there were an estimated 300000 Pochard in the north-east/north-west European population (Delany et al. 1999). With a constant decline of 3.35\%/year, the total population should now be less than 150000 (Nagy et al. 2014). Numbers of Pochard were expected to be higher in the ORE because of the reduced ice cover. However, we found a reduction in the importance of the estuary to this species (Table 3), corresponding with its global decline (Aunins et al. 2013; Nagy et al. 2014; Wetlands International 2016). Pochard behaves more like Tufted Duck than Scaup over winter in being more dispersed and occurring on smaller bodies of water (e.g. Marchowski and Lawicki 2011; Marchowski et al. 2013; Neubauer et al. 2015). This implies that individuals may also be wintering outside the study area, e.g. on the numerous water bodies of the Pomeranian Lake District, like Tufted Duck. This local decline, however, seems to be driven by the species' global decline, despite the emergence of better conditions for wintering that might favor population growth.

Smew populations wintering in northern, western and central Europe increased at 1.97\%/year between the late 1980s and 2012 (Nagy et al. 2014); in the Baltic Sea region numbers increased by 30\% between 1991 and 2010 (Aunins et al. 2013). Although Smew cannot be classified as a piscivore in the same way as Goosander (and Red-breasted Merganser M. serrator), it does feed on very small fish and on small invertebrates (Carboneras and Kirwan 2016 c). Though more dependent on shallow water than Goosander, Smew generally forages on mobile types of food. So even if shallow waters freeze over, it may remain on site and search for 
384 food in deeper water, which is what we have observed. We found that today, the ORE is of less

385 importance to Smew (Table 3) as illustrated by the northward and eastward shift in wintering

386 area boundaries due to climate warming (Pavon-Jordan et al. 2015; Nilsson and Haas 2016).

387

388

389

390

391

392

393

394

395

396

397

398

399

400

401

402

403

404

405

406

\section{Species with no changes in the population index in the study area}

Coot populations wintering in north-west Europe increased by $0.19 \% /$ year between the late 1980s and 2012 (Nagy et al. 2014), but in the Baltic region, there was a 60\% decline between 1991 and 2010 (Aunins et al. 2013). We have found no changes in Coot numbers in the ORE over the last 25 years (Table 3). Likewise, no changes in numbers were recorded between 1975 and 2010 at wintering sites in warmer areas to the south-west (the Netherlands) (Hornman et al. 2012). Long-term figures for Sweden (1971-2015), while not revealing any distinct increase, do show that Coot populations fluctuated, rising during mild periods and falling during cold periods (Nilsson and Haas 2016). The expected increase in numbers due to improvements in habitat quality did not happen. Factors such as pressure from American mink Neovison vison, which is responsible for the decline of Coot in many places (e.g. Ferreras and Macdonald 1999), may have held back potential increases. Moreover, compared to the bottom-diving Ducks, Coot is more sensitive to cold weather: a study by Fredrickson (1969) demonstrated high mortality after periods of severe weather (also reflected in the results of Swedish breeding bird surveys Leif Nilsson pers. com.) but that the population recovered during mild winters. This factor may also be the reason for the different reactions of Coot and diving ducks to the cold.

Goldeneye populations wintering in north-west and central Europe increased at 0.26\%/year between the late 1980s and 2012 (Nagy et al. 2014) and increased in the Baltic Sea region by 50\% between 1991 and 2010 (Aunins et al. 2013). This corresponds to the data provided by Lehikoinen et al (2013), an increase in numbers in the northern Baltic wintering area 
407 (Finland and N Sweden), but a decline in the southern part of its wintering range (Switzerland,

408 France). In our work, we found the relative number of Goldeneye in the ORE to be stable in the

409 period 1992-2016 (Table 3). This again tallies with the findings of Lehikoinen et al. (2013) that

410 duck abundances are independent of temperature in the central part of the flyway. This is

411 probably why the shift in wintering range is not perceptible in our study area but is more

412 pronounced at other, e.g. Swedish wintering sites, where numbers have increased (Nilsson and

413 Haas 2016) but not in the Netherlands, where they have declined (Hornman et al. 2012).

the early 1990s (Nagy et al. 2014); moreover, numbers in the Baltic Sea between 1991 and 2010 did not change significantly (Aunins et al. 2013); we also found non-significant changes in the

ORE.(Table 3). As in the case of Goldeneye, the explanation is that in the central part of the

418 flyway, species abundances are independent of temperature. In other areas, observations indicate

419 a shift farther to the north and east in the wintering range as a result of climate warming

420 (Hornman et al. 2012; Lehikoinen et al. 2013; Nilsson and Haas 2016).

\section{Conclusion}

Climate change can influence the distribution of overwintering waterbirds. Apart from 427 climate changes, however, feeding ecology, interspecific competition, fishery and other human- 
428 related disturbance may be also important and should be taken into consideration (Quan et al.

429 2002, Žydelis et al. 2009, Clavero et al., 2011; Eglington \& Pearce-Higgins, 2012). Protected

430 areas covered by our study will be more important for some species (Scaup and Tufted Duck) but

431 less so for others (Smew). Taking into account the large abundance of the target species regularly

432 present in the ORE, conservation measures applied here will have a large impact on entire

433 populations and will be particularly important for Scaup. Shifts in species distributions should be

434 accounted for in future management plans for Special Protection Areas of the European Natura

4352000 network. Our results add new insight to the problem of wintering waterbirds protection and

436 can help to shape conservation policy in the southern Baltic.

\section{Acknowledgements}

We thank all the people who took part in the fieldwork - mainly members of the West-

Pomeranian Nature Society - but especially the most active among them during the entire study

period: Michał Barcz, Ryszard Czeraszkiewicz, Sebastian Guentzel, Michał Jasiński, Zbigniew

Kajzer, Jacek Kaliciuk, Krzysztof Kordowski, Aneta Kozłowska, Wojciech Mrugowski,

Siuda, Paweł Stańczak and Maciej Przybysz. We are grateful to Leif Nilsson, James Roper and and to Peter Senn, who kindly improved our English.

\section{References}


Aharon-Rotman Y., Buchanan K.L., Clark N.J., Klaassen M., Buttemer W.A. 2016. Why fly the extra mile? Using stress biomarkers to assess wintering habitat quality in migratory shorebirds. Oecologia 182: 385-395.

Alerstam T. 1990. Bird migration. Cambridge University Press, Cambridge.

Aunins A., Nilsson L., Hario M., Garthe S., Dagys M., Petersen I.K., Skov H., Lehikoinen A., Roos M.M., Ranft S., Stipniece A., Luigujoe L., Kuresoo A., Meissner W., Korpinen S.2013. Abundance of waterbirds in the wintering season. HELCOM Core Indicator Report. Online. Available: http://www.helcom.fi/.

Bellebaum, J., Schirmeister, B., Sonntag, N., Garthe, S. 2012. Decreasing but still high: bycatch of seabirds in gillnet fisheries along the German Baltic coast. Aquat. Conservat. Mar. Freshwat. Ecosyst. 23, 210-221.

BirdLife International 2004. Birds in Europe, population estimate, trends and conservation status. Cambridge UK: BirdLife Conservation Series No.12.

BirdLife International 2015 a. European Red List of Birds. Luxembourg: Office for Official Publications of the European Communities.

BirdLife International. 2015 b. Aythya ferina. The IUCN Red List of Threatened Species 2015:e.T22680358A82571892. http://dx.doi.org/10.2305/IUCN.UK.20154.RLTS.T22680358A82571892.en. Downloaded on 23 October 2016.

Blums P., Mednis A., Bauga I., Nichols J.D., Hines J.E. 1996. Age-specific survival and philopatry in three species of European ducks: a long-term study. Condor 98: 61-74.

Burnham, K.P. \& Anderson, D.R. 2002. Model Selection and Multimodel Inference: A Practical Information-Theoretic Approach. Springer, New York/

Carboneras C. \& Kirwan G.M. 2016 a. Greater Scaup (Aythya marila). In: del Hoyo, J., Elliott, A., Sargatal, J., Christie, D.A. \& de Juana, E. (eds.). Handbook of the Birds of the World Alive. Lynx Edicions, Barcelona. (retrieved from http://www.hbw.com/node/52912 on 23 October 2016).

Carboneras, C. \& Kirwan, G.M. 2016 b. Tufted Duck (Aythya fuligula). In: del Hoyo, J., Elliott, A., Sargatal, J., Christie, D.A. \& de Juana, E. (eds.). Handbook of the Birds of the World Alive. Lynx Edicions, Barcelona. (retrieved from http://www.hbw.com/node/52910 on 23 October 2016).

Carboneras, C. \& Kirwan, G.M. 2016 c. Smew (Mergellus albellus). In: del Hoyo, J., Elliott, A., Sargatal, J., Christie, D.A. \& de Juana, E. (eds.). Handbook of the Birds of the World Alive. Lynx Edicions, Barcelona. (retrieved from http://www.hbw.com/node/52927 on 21 October 2016).

Carboneras, C. \& Kirwan, G.M. 2016 d. Goosander (Mergus merganser). In: del Hoyo, J., Elliott, A., Sargatal, J., Christie, D.A. \& de Juana, E. (eds.). Handbook of the Birds of the World Alive. Lynx Edicions, Barcelona. (retrieved from http://www.hbw.com/node/52931 on 21 October 2016).

Carboneras, C., Christie, D.A. \& Kirwan, G.M. 2016. Common Goldeneye (Bucephala clangula). In: del Hoyo, J., Elliott, A., Sargatal, J., Christie, D.A. \& de Juana, E. (eds.). Handbook of the Birds of the World Alive. Lynx Edicions, Barcelona. (retrieved from http://www.hbw.com/node/52925 on 23 October 2016).

Clavero, M., Villero, D. \& Brotons, L. 2011 Climate change or land use dynamics: do we know what climate change indicators indicate? PLoS ONE, 6, e18581.

Coppack, T., Both, C., 2002. Predicting life-cycle adaptation of migratory birds to global climate change. Ardea 90: 369-378. 
495

496

497

498

499

500

501

502

503

504

505

506

507

508

509

510

511

512

513

514

515

516

517

518

519

520

521

522

523

524

525

526

527

528

529

530

531

532

533

534

535

536

537

538

539

Cramp, S. \& Simmons, K.E.L. eds. 1977. The Birds of the Western Palearctic. Vol. 1. Oxford University Press, Oxford.

Cresswell, W. 2014. Migratory connectivity of Palaearctic - African migratory birds and their responses to environmental change: the serial residency hypothesis. Ibis 156: 493-510. doi:10.1111/ibi.12168

Guentzel S., Ławicki Ł., Marchowski D., Kajzer Z., Barcz M., Racławski B., Sołowiej M., Staszewski A. 2012. The Szczecin Lagoon PLB320009. In: Ławicki Ł., Guentzel S. editors. Important Bird Areas in Poland - the inventory of non-breeding species in 2011/2012 season. ECO-EXPERT, Szczecin. (In Polish).

Czeraszkiewicz R., Haferland H.J., Oleksiak A. 2004. The results of waterbirds count in the Western Pomerania in the season 2003/2004. In: Czeraszkiewicz R., Oleksiak A. Waterbirds in Western Pomerania. The results of counts in 2003/2004, ecology and conservation, ZTO-PZŁ, Szczecin. 2004. pp. 5-16. (in Polish with German summary).

De Leeuw J.J. 1999. Food intake rates and habitat segregation of Tufted Duck Aythya fuligula and Scaup Aythya marila exploring Zebra Mussels Dreissena polymorpha. Ardea 87: 1531.

del Hoyo J. and Collar N.J. 2014. HBW and BirdLife International Illustrated Checklist of the Birds of the World. Volume 1: Non-passeriformes. Lynx Edicions, Barcelona.

Delany S.N., Reyes C., Hubert E., Phil S., Rees E., Haanstra L., van Strien A.1999. Results from the International Waterbird Census in the Western Palearctic and Southwest Asia 1995 and 1996. Wetland International Publ. Wageningen, The Netherlands.

Dillingham P.W., Fletcher D. 2008. Estimating the ability of birds to sustain additional humancaused mortalities using a simple detection rule and allometric relationship. Biological Conservation 141: 1783-1792.

EEA - The European Environment Agency data obtained from: http://www.eea.europa.eu/dataand-maps/figures/maximum-extents-of-ice-cover 10.02.2017

Eglington, S.M. \& Pearce-Higgins, J.W. 2012. Disentangling the relative importance of changes in climate and land-use intensity in driving recent bird population trends. PLoS ONE, 7, e30407

Ferreras P., Macdonald D. W. 1999. The impact of American mink Mustela vison on water birds in the upper Thames. J Appl Ecol 36: 701-708.

Finnish Meteorological Institute data obtained from: http://en.ilmatieteenlaitos.fi/ 10.02.2017

Girjatowicz J.P. 1990. Ice cover atlas for Polish Baltic Coastal waters. Akademia Rolnicza, Szczecin (in Polish).

Girjatowicz J.P. 2005. Ice conditions in Szczecin Lagoon and the Pomeranian Bay. In: Borówka R.K., Musielak S. (eds), Środowisko przyrodnicze wybrzeży Zatoki Pomorskiej i Zalewu Szczecińskiego. Uniwersytet Szczeciński, Szczecin, pp. 126-138 (in Polish).

Girjatowicz J.P. 2011. Ice Conditions on the Southern Baltic Sea Coast. J. Cold Reg. Eng.25:115.

Hornman M., van Roomen M., Hustings F., Koffijberg K., van Winden E., Soldaat L. 2012. Population trends in wintering and migrating waterbirds in The Netherlands in 1975-2010 (in Dutch with English summary). Limosa 85: 97-116

Jankowiak, Ł., Antczak, M., Kwieciński, Z., Szymański, P., Tobolka, M., Tryjanowski, P., 2015a. Diurnal raptor community wintering in an extensively used farmland. Ornis Fennica 92: 76-86. 
540

541

542

543

544

545

546

547

548

549

550

551

552

553

554

555

556

557

558

559

560

561

562

563

564

565

566

567

568

569

570

571

572

573

574

575

576

577

578

579

580

581

582

583

584

Jankowiak, Ł., Polakowski, M., Kułakowski, T., Świętochowski, P., Tumiel, T., Broniszewska, M., Takács, V., 2015b. Habitat and weather requirements of diurnal raptors wintering in river valleys. Biologia (Bratisl). 70, 1136-1142.

Johansgard P.A. 1978. Ducks, Geese, and Swans of the World. University of Nebraska Press. Lincoln and London.

Kaliciuk J., Oleksiak A., Czeraszkiewicz R. 2003. The results of counts of waterbirds in the Western Pomerania in the season 2002/2003. In: Czeraszkiewicz R., Oleksiak A. Waterbirds in Western Pomerania. The results of counts in 2002/2003, ecology and conservation. ZTO-PZŁ, Szczecin. 2003. pp. 14-25. (in Polish with German summary).

Kear, J. ed. 2005. Ducks, geese and swans. Oxford University Press, Oxford.

Komdeur J., Bertelsen J., Cracknell G. 1992. Manual for aeroplane and ship surveys of waterfowl and seabirds. IWRB Special Publication No.19. IWRB, Slimbridge, U.K.

Larsen K.1992. New figures of seaduck winter population in the Western Palearctic. IWRB Seaduck Bulletin No.1 Jan.1992.

Lehikoinen A., Jaatinen K., Vahatalo A.V., Preben C., Crowe O., Deceuninck B., Hearn R., Holt C.A., Hornman M., Keller V., Nilsson L., Langendoen T., Tomankova I., Wahl J., Fox A.D. 2013. Rapid climate driven shifts in wintering distributions of three common waterbird species. Global Change Biology: 19, 2071-2081, doi: 10.1111/gcb.12200

Ludwichowski, I., Barker, R. \& Bräger, S. 2002. Nesting area fidelity and survival of female Common Goldeneyes Bucephala clangula: are they density-dependent? Ibis 144: 452460.

Ławicki Ł, Czeraszkiewicz R, Guentzel S, Jasiński M, Kajzer Z, Kaliciuk J, Oleksiak A. 2008. Wintering of Waterbirds in the Western Pomerania in the years 2002-2008. Not. Orn. 49: 235-244. (in Polish with English summary).

Marchowski D., Ławicki Ł. 2011. Numbers of Waterfowl in Western Pomerania in the 2009/2010 season. Ptaki Pomorza 2: 159-166 (in Polish with English summary).

Marchowski D, Ławicki Ł. 2012. Numbers of Waterfowl in Western Pomerania in the season 2010/2011. Ptaki Pomorza 3: 129-134 (in Polish with English summary).

Marchowski D., Ławicki Ł., Guentzel S. 2013. Numbers of Waterfowl in Western Pomerania in the season 2010/2011. Ptaki Pomorza 4: 149-169. (in Polish with English summary).

Marchowski D., Neubauer G., Ławicki Ł., Woźniczka A., Wysocki D., Guentzel S., Jarzemski M. 2015. The importance of non-native prey, the Zebra Mussel Dreissena polymorpha, for the declining Greater Scaup Aythya marila: a case study at a key European staging and wintering site. PLoS ONE 10(12): e0145496.

Marchowski D., Jankowiak Ł., Wysocki D. 2016. Newly demonstrated foraging method of Herring Gulls and Mew Gulls with benthivorous diving ducks during the nonbreeding period. Auk 133: 31-40.

Meller K. 2016. The impacts of temperature on the long-term variation in migration and breeding performance of birds. PhD dissertation. The Helsinki Lab of Ornithology The Finnish Museum of Natural History Luomus Zoology Unit University of Helsinki Finland. Available

at: https://helda.helsinki.fi/bitstream/handle/10138/160724/The_impa.pdf?sequence=1

Musil P., Musilová Z., Fuchs R., Poláková S. 2011. Long-term changes in numbers and distribution of wintering waterbirds in the Czech Republic, 1966- 2008. Bird Study 58: 450-460. 
585

586

587

588

589

590

591

592

593

594

595

596

597

598

599

600

601

602

603

604

605

606

607

608

609

610

611

612

613

614

615

616

617

618

619

620

621

622

623

624

625

626

627

628

629
Nagy S., Flink S., Langendoen T. 2014. Waterbird trends 1988-2012. Results of trend analyses of data from the International Waterbird Census in the African-Eurasian Flyway. Wetlands International. Ede, the Netherlands.

Neubauer G., Meissner W., Chylarecki P., Chodkiewicz T., Sikora A., Pietrasz K., Cenian Z., Betleja J., Gaszewski K., Kajtoch Ł., Lenkiewicz W., Ławicki Ł., Rohde Z., Rubacha S., Smyk B., Wieloch M., Wylegała P. Zieliński P. 2015. Monitoring of Birds in Poland in years 2013-2015. Newsletter of Nature Monitoring 13: 1-92.

Newton, I., 2008. The migration ecology of birds. Academic Press, London, United Kingdom.

Nilsson L., Haas F. 2016. Distribution and numbers of wintering waterbirds in Sweden in 2015 and changes during the last fifty years. Ornis Svecica 26:3-54.

Pavón-Jordan D., Fox A., D., Clausen P., Dagys M., Deceuninck B., Devos K., Hearn R. D., Holt C. A., Hornman M., Keller V., Langendoen T., Ławicki Ł., Lorentsen S., H., Luiguj L., Meissner W., Musil P., Nilsson L., Paquet J. Y., Stipniece A., Stroud D. A., Wahl J., Zenatello M., Lehikoinen A. 2015. Climate-driven changes in winter abundance of a migratory waterbird in relation to EU protected areas. Diversity Distrib. 21: 571-582.

Pearce J.M., Reed J.A., Flint P.L. 2005. Geographic variation in survival and migratory tendency among North American Common Merganser. Journal of Field Ornithology 76: 109-118.

Perdeck A. C. 1998. Poisson regression as a flexible alternative in the analysis of ring-recovery data. Euring Newsletter 2: 37-42.

Quan, R.C., Wen, X.J., Yang, X.J., 2002. Effects of human activities on migratory waterbirds at Lashihai Lake. Biological Conservation 108, 273-279.

Radziejewska T., Schernewski G. 2008. The Szczecin (Oder) Lagoon. In: Schiewer U, editor. Ecology of Baltic Coastal Waters. Berlin Heidelberg: Springer, pp. 116-117.

Runge M. C., Sauer J.R., Avery M.L., Blackwell B.F., Koneff M.D. 2009. Assessing allowable take of migratory birds. Journal of Wildlife Management. 73: 556-565.

Skov H., Heinänen S., Žydelis R., Bellebaum J., Bzoma S., Dagys M., Durinck J., Garthe S., Grishanov G., Hario M., Kieckbusch J.J., Kube J., Kuresoo A., Larsson K., Luigujoe L., Meissner W., Nehls H. W., Nilsson L., Petersen I.K., Roos M. M., Pihl S., Sonntag N., Stock A., Stipniece A., Wahl J. 2011. Waterbird Populations and Pressures in the Baltic Sea. Nordic Council of Ministers, Copenhagen.

Schröder J. 2015. Does ice coverage in the Baltic Sea affect numbers of diving ducks wintering in the Netherlands? Limosa 88: 22-30.

Stańczykowska A., Lewandowski K., Czarnoleski M. 2010. Distribution and densities of Dreissena polymorpha in Poland - past and present. In: Van der Velde G, Rajagopal S, Bij de Vaate A, editors. The Zebra Mussel in Europe. Margraf Publishers, Weikersheim: pp. 119-132Stempniewicz L. 1974. The effect of feeding of the Coot Fulica atra on the character of shoals of Dreissena polymorpha in the Lake Gopło. Acta Univ. Nicolai Copernici 34: 83-103.

Stempniewicz L. 1974. The effect of feeding of the Coot Fulica atra on the character of shoals of Dreissena polymorpha in the Lake Gopło. Acta Univ. Nicolai Copernici 34: 83-103.

Stempniewicz L., Meissner W. 1999. Assessment of the zoobenthos biomass consumed yearly by diving ducks wintering in the Gulf of Gdańsk (southern Baltic Sea). Ornis Svecica 9: $143-154$.

Stocker T.F., Qin D., Plattner G.K., Tignor M., Allen S.K., Boschung J., Navels A., Xia Y., Bex V. Midgley P.M. eds. 2013. Climate Change 2013: The Physical Science Basis. 
630

631

632

633

634

635

636

637

638

639

640

641

642

643

644

645

646

647

648

649

650

651

652

653

654

655

656

657

658

659

660

661

662

663

664

665

666

667

668

669

670

671

672

673

674

675

Contribution of Working Group I to the Fifth Assessment Report of the Intergovernmental Panel on Climate Change. Cambridge University Press.

Taylor, B. \& Kirwan, G.M. 2016. Common Coot (Fulica atra). In: del Hoyo, J., Elliott, A., Sargatal, J., Christie, D.A. \& de Juana, E. (eds.). Handbook of the Birds of the World Alive. Lynx Edicions, Barcelona. (retrieved from http://www.hbw.com/node/53695 on 21 October 2016).

van Erden M. R., de Leeuw J.J. 2010. How Dreissena sets the winter scene for water birds: dynamic interaction between diving ducks and zebra mussels. In: van der Velde G., Rajagopal S., bij de Vaate A. The Zebra Mussel in Europe. 2010. Backhuys Publ., Leiden, The Netherlands.

Wacker A. 2010. Careless youth? Food in the early life-stages of zebra mussels. In: Van der Velde G., Rajagopal S., bij de Vaate A. The Zebra Mussel in Europe. 2010. Backhuys Publishers, Leiden, The Netherlands.

Weatherbase. 2016.: Historical Weather for Szczecin, Poland. (access: 29.01.2016), available at: http://www.weatherbase.com/.

Wetlands International. Guidance on waterbird monitoring methodology: Field Protocol for waterbird counting. Wetlands International, Wageningen. 2010. Available from: http://www.wetlands.org.

Wetlands International 2016. "Waterbird Population Estimates". Retrieved from wpe.wetlands.org on Tuesday 11 Oct 2016

Wiktor J. 1969. Biology of Dreissena polymorpha (Pall.) and its importance on Szczecin Lagoon. Stud. Mater. Mor. Inst. Ryb., Gdynia. (in Polish).

Wilk T., Jujka M., Krogulec J., Chylarecki P. (eds.) 2010. Important Bird Areas of international importance in Poland. OTOP, Marki.

Wolnomiejski N., Witek Z. 2013. The Szczecin Lagoon Ecosystem: The Biotic Community of the Great Lagoon and its Food Web Model. Versita Ltd. London.

Wolnomiejski N., Woźniczka A. 2008. A drastic reduction in abundance of Dreissena polymorpha Pall. in the Skoszewska Cove (Szczecin Lagoon, River Odra estuary): effects in the population and habitat. Ecological Questions 9: 103-111.

Žydelis, R., Bellebaum, J., Österblom, H., Vetemaa, M., Schirmeister, B., Stipniece, A., Dagys M., van Eerden M., Garthe S. 2009. Bycatch in gillnet fisheries - An overlooked threat to waterbird populations. Biol. Conserv. 142, 1269-1281.

Zuur, A., Ieno, E.N., Walker, N., Saveliev, A.A., Smith, G.M. 2009. Mixed Effects Models and Extensions in Ecology with R. Springer-Verlag, New York. 
676

677

678

679

680

681

682

683

684

685

686

687

688

689

690

691

692

693

694

Table 1. Regional flyway populations and annual trends (after Nagy et al. 2014) for seven species of waterbirds using the Odra River Estuary.

(1) Target species. (2) Functional group: B - bottom-feeders, P - piscivores. (3) Estimated number of individuals from regional flyway population in 1992, the numbers are presented in thousands. (4) Estimated number of individuals from regional flyway population in 2012 , the numbers are presented in thousands. (5) Population trend \% per annum - long term assessment. (6) Significances of changes.

\begin{tabular}{lrrrrr}
\hline Species (1) & $\begin{array}{r}\text { Functional } \\
\text { group (2) }\end{array}$ & $\begin{array}{r}\text { Number of } \\
\text { individuals } \\
(1992)(3)\end{array}$ & $\begin{array}{r}\text { Number of } \\
\text { individuals } \\
(2012)(4)\end{array}$ & $\begin{array}{r}\text { Population } \\
\text { trend \% p.a. (5) }\end{array}$ & Significance \\
of changes (6)
\end{tabular}


Table 2. Results of general linear mixed models for seven species showing the influence of ice cover, bottom-feeders (denoted by B, Scaup, Tufted Duck, Pochard, Goldeneye, Coot) and piscivores (denoted

725 effects.

\begin{tabular}{lllll}
\hline Model Term & Coefficient & Std. Error & $\mathrm{t}$ & $P$ \\
\hline Intercept & 26.553 & 11.619 & & \\
Ice cover & 0.014 & 0.006 & 2.375 & $\mathbf{0 . 0 1 8}$ \\
Season & -0.013 & 0.006 & -2.204 & $\mathbf{0 . 0 2 8}$ \\
Max ice & -0.114 & 0.040 & -2.824 & $\mathbf{0 . 0 0 5}$ \\
Feed[B] & -38.751 & 11.959 & -3.240 & $\mathbf{0 . 0 0 1}$ \\
Season*Feed[B] & 0.019 & 0.006 & 3.212 & $\mathbf{0 . 0 0 1}$ \\
Ice cover*Feed[B] & -0.044 & 0.007 & -6.623 & $<\mathbf{0 . 0 0 1}$ \\
Max ice*Feed[B] & 0.094 & 0.046 & 2.071 & $\mathbf{0 . 0 3 9}$ \\
Species (r) & 0.074 & 0.048 & & \\
Method (r) & 0.015 & 0.020 & & \\
Month (r) & 0.001 & 0.002 & & \\
& & & & \\
\hline
\end{tabular}


728

729

730

731

Peer] reviewing PDF | (2016:12:15149:5:0:NEW 24 Jun 2017) 
732

\begin{tabular}{lllll}
\hline Species & \%b.p.1992 & \%b.p.2016 & $\begin{array}{l}\text { Mean1992- } \\
\text { 2016 } \pm \text { SE }\end{array}$ & $\begin{array}{l}\text { Trend } \\
\text { ORE }\end{array}$ \\
\hline Greater Scaup & & & $14.17 \pm 2.84$ & $\uparrow$ \\
Tufted Duck & 5.68 & 12.60 & $2.61 \pm 0.25$ & $\uparrow$ \\
Common Goldeneye & 2.87 & 4.79 & $1.21 \pm 0.14$ & $\rightarrow$ \\
Eurasian Coot & 4.48 & 0.63 & $0.61 \pm 0.07$ & $\rightarrow$ \\
Goosander & 0.86 & 0.68 & $6.85 \pm 1.01$ & $\rightarrow$ \\
Smew & 12.59 & 1.80 & $7.01 \pm 1.27$ & $\downarrow$ \\
Common Pochard & 7.04 & 2.76 & $0.62 \pm 0.09$ & $\downarrow$ \\
\hline
\end{tabular}

Table 3. Population index trends in the Odra River Estuary (ORE) for the regional biogeographic (flyway) population (b.p.) of diving waterbirds showing the percentage of the flyway population in 1992; the percentage of the flyway population in 2016; the mean percentage of the flyway population in the period $1992-2016 \pm$ standard error; and the trend in the period $1992-2016$.

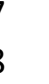


772 Figure 1. The Odra River Estuary, north-western Poland.

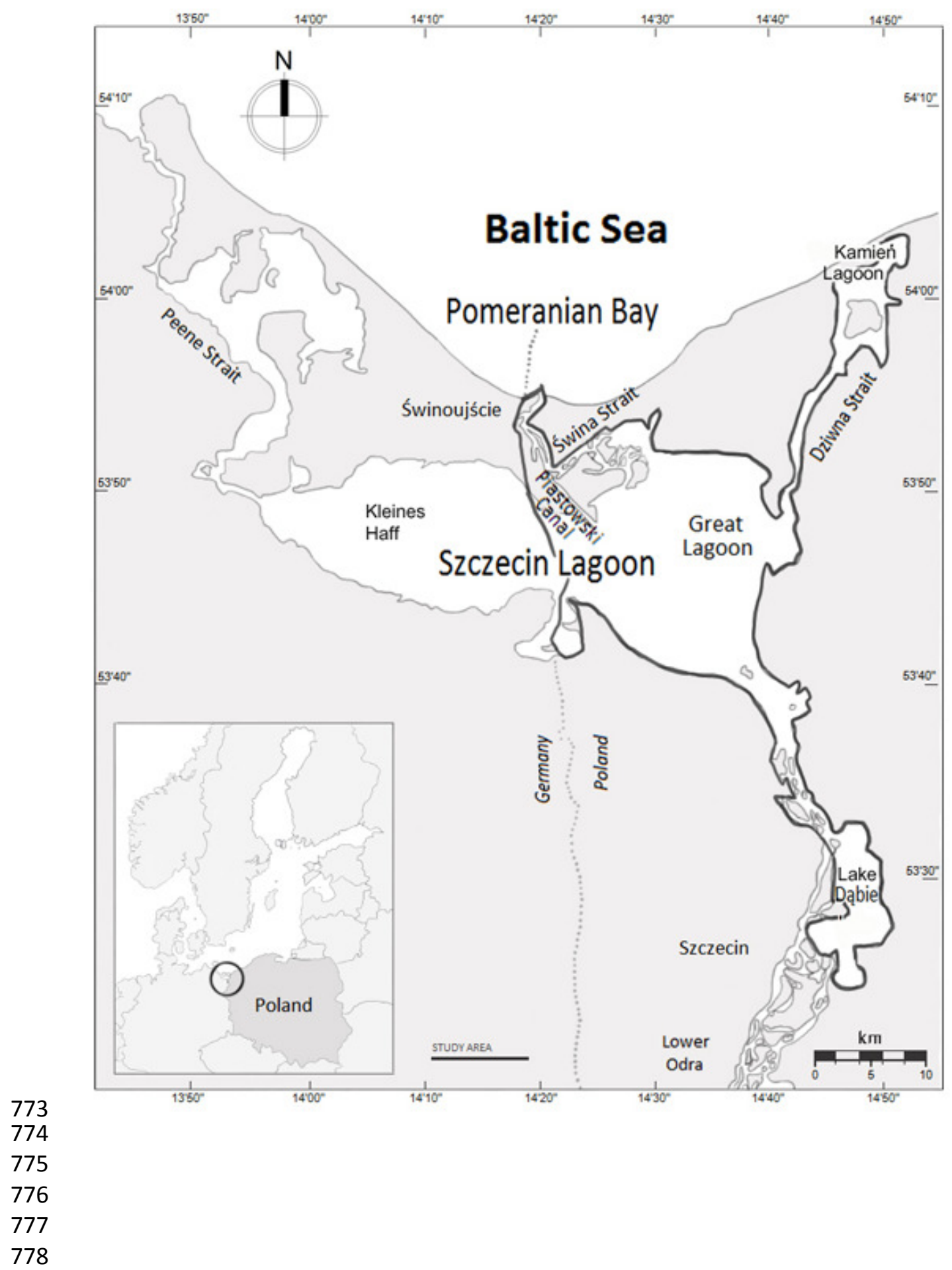


Figure 2 A. Predicted results of the general linear mixed model showing the changes of the percentage of the target species population in the Odra River Estuary during years 1992 - 2016. The predicted values

788

789

790

791

792 were obtained from the model where we added species as a fixed variable. The model's parameters are listed in Table S3 in the Supplementary material. Dashed lines - the gap with birds data. B) Changes in the ice cover duration in the Odra River Estuary during years 1992 - 2016. Results of a generalized linear model (with negative binomial error distribution) - correlation between year and winter ice. Dotted lines show $95 \%$ confidence intervals bounds.
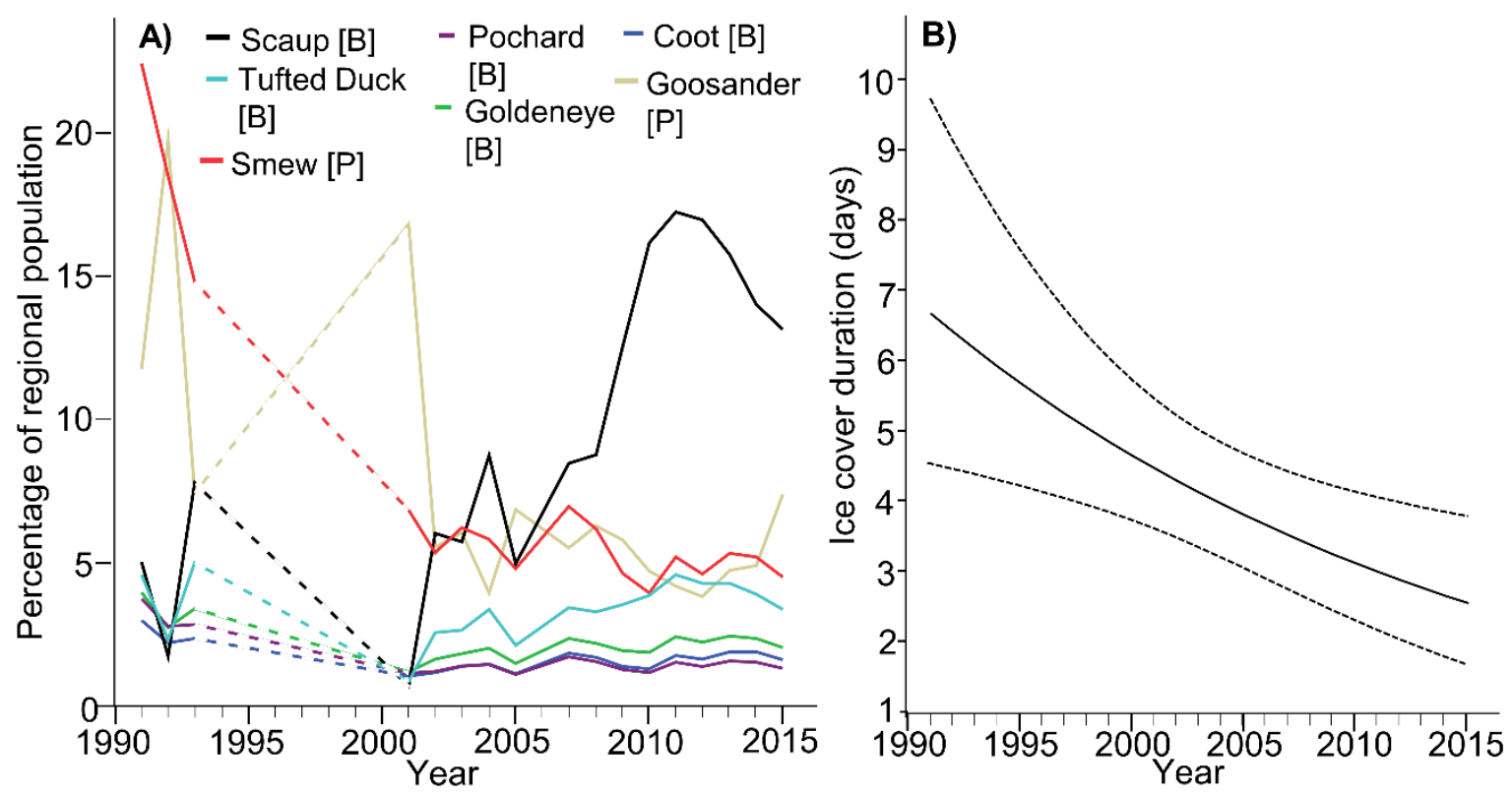